\title{
Virtus Academy - driving the development of elite sport for athletes with intellectual impairment
}

\author{
Debbie Van Biesen \\ Received: 18 ${ }^{\text {th }}$ October 2021; Accepted: $10^{\text {th }}$ November 2021; Published: $16^{\text {th }}$ November 2021
}

In a fully inclusive society, all people should have the right to follow the self-chosen pathway in physical activity or sport, on any end of the continuum from purely recreational to high-performance competition. Yet societies are far from being fully inclusive as people with impairments face several limitations to participate (Townsend, Huntley, Cushion \& Culver, 2021) or to perform sport at the highest level (Burns, 2015). Despite several limitations that people with intellectual impairment (II) might face, it is equally important to acknowledge their strengths and aspirations. When the optimal support is available, in combination with the right combination of talent, motivation and ambition, people with II can become athletes and achieve elite performance goals. Elite sport creates role models and can change attitudes, which might benefit the development of grassroots physical activity.

The three sports on the Paralympic Games program which currently include the II-class are swimming, table tennis and athletics (Van Biesen, Burns, Mactavish, Van de Vliet, \& Vanlandewijck, 2021). A total of 161 II-athletes, 90 males and 71 females, competed at the Tokyo 2020 Paralympic Games. This is a small but significant percentage of all competitors, making the Paralympic Games a showcase for para-athletes with physical, visual, and intellectual impairments.

Competitive sport for athletes with II is often associated with Special Olympics by the general public. This is not surprising because Special Olympics International (SOI) reaches over 3.5 million athletes with II and unified partners worldwide, in a wide variety of sports and events such as the World Games (SOI, 2020). One of the most apparent differences between Special Olympics and Paralympics is that both organisations have a clearly distinct mission, with SOI focusing on participation, inclusion, and experiencing joy (https://www.specialolympics.org) whereas, the Paralympic Committee's mission is to enable Paralympic athletes to achieve sporting excellence (https://www.paralympic.org).

In addition to SOI and the International Paralympic Committee (IPC), Virtus World Intellectual Impairment Sport (Virtus, previously the International Federation for Athletes with Intellectual Impairments; INAS) is the third key international organization governing competitive sport with a competitive offer in 17 sports (https://www.virtus.sport). Virtus is a founding member of IPC and has a membership of over 500,000 athletes with neurodiverse backgrounds from more than 90 nations globally, notably throughout Europe, Africa, Asia, North and South/Central America and Oceania. Neurodiversity includes neurodevelopmental disorders such as intellectual impairment (class II-1), intellectual impairment with additional health conditions or genetic disorders such as Down Syndrome (class II-2) and autism spectrum disorder (class II-3). Virtus athletes must have one of these eligible impairments. Whereas intellectual disability is the term commonly used internationally to denote the complexities of the impairment in interaction with environmental demands, we use II throughout this editorial to be consistent with the IPC's evidence-based classification approach and the World Health Organization's International 
Classification of Functioning, Disability and Health (ICF). The ICF is the globally recognized framework for defining and measuring disability and health (https://www.who.int/standards/classifications/).

Virtus has the mission to drive the development of elite sport for athletes with II globally. To achieve this goal, the organization launched the Virtus Academy in 2021 (https://www.thevirtusacademy.org), to work around five pillars (i.e., athlete development, coach education, science, eligibility \& classification, and awareness in society). The main actions of Virtus Academy in the first year were focused around 'science' and 'coach education', the two pillars that will be highlighted in this editorial.

\section{Sport science underpinning elite II performance}

Although sport science in the Paralympics is a growing area of research (TuakliWosornu \& Derman, 2018), there are major steps to be taken before the professionalization of II-sport reaches the same level as parasport. In general, the challenges in elite II-sport performance from a sport-science perspective are multifactorial and multidisciplinary. Athletes with II are an under-researched population, and more insight is needed across different areas such as psychology, sports medicine, and exercise physiology specifically for this population. Close cooperation between sport scientists from non-parasports and IIexperts is warranted, since both areas of expertise can reinforce each other transferring basic knowledge, theoretical models, and sport-specific applications. The Virtus Academy Scientific Advisory Committee (VASCOM) was created to identify the key areas for future research, fill the existing gaps and enhance athlete and coach development.

Research to enhance performance of athletes with II can be closely aligned with the body of research performed in the context of evidence-based classification. The central question in classification is, if and, to what extent the impairment impacts on sport performance (Van Biesen et al., 2021). For coaches and support staff this knowledge is imperative in order to help their elite II-athletes enhance sport performance despite limitations in cognitive and adaptive functioning.

\section{Coaching education}

Another key area to improve the inclusion of II-athletes is para-coach education, the second central pillar of Virtus Academy. Burns \& Johnson (2020) interviewed coaches who work with elite level II-athletes around Europe (as part of the https://www.idealproject.org) and reported they were mostly reliant on self-learning and learning from other coaches working in II. There is no structure or system in place for specific coach education to specialize in the field of II-sport.

In general, research into coaching in disability sport appears to be traditionally underrepresented in the literature (Shapiro \& Pitts, 2014), although it is a rapidly growing area. The lack of available resources for coaches is one of the major barriers reported for successful inclusion of athletes with disabilities, including those with II (Townsend, Smith, \& Cushion, 2015). Appropriate support for elite sport coaches is crucial to optimize performance and prevent injuries or other negative consequences of the training (e.g., psychosocial). Only a handful of studies have focused explicitly on coaching II-athletes. One of the main goals of Virtus Academy is to build on the available knowledge base generated from the IDEAL project to develop evidence-based resources, practical toolboxes and training courses for high level coaches to optimize their training practice.

\section{Conclusion}

There is insufficient equality with respect to opportunities, funding, access to high-level coaches and access to sporting facilities for athletes with II. There are many reasons for this 
inequality, and there is no one-size-fits-all solution to this problem; however, there is a large gap to fill with respect to sport science and coach education. Virtus Academy strives to become a global hub of research training and education to drive the development of elite IIsports. Apart from the work done in the areas of science and coach education, the three other pillars are, at least, as important to target future projects in the areas of athlete development (e.g., athlete leadership programs), eligibility and classification (e.g., support international federations that aim to bring new sports on the Paralympic program) and awareness (e.g., help people and organisations coping efficiently with the negative consequences of the COVID-19 pandemic; see Ng 2020).

\section{Author affiliations:}

1 KU Leuven, Faculty of Movement and Rehabilitation Sciences, Department of Rehabilitation Sciences, Research Unit Adapted Physical Activity and Psychomotor Rehabilitation

2 Virtus Academy Manager, Virtus Intellectual Impairment Sport

* Correspondence: Debbie.vanbiesen@kuleuven.be

\section{References}

Burns, J. (2015). The impact of intellectual disabilities on elite sports performance. International Review of Sport and Exercise Psychology, 8(1), 251-267. https://doi.org/10.1080/1750984X.2015.1068830.

Burns, J., \& Johnson, M. (2020). Identifying best practices in sports coaching for athletes with intellectual disabilities - coach and athlete perspectives. Canterbury Christ church University. https://www.idealproject.org/resources accessed on 25 June 2021.

$\mathrm{Ng}, \mathrm{K}$. (2020). Adapted physical activity through COVID-19. European Journal of Adapted Physical Activity 13(1), 1-3. https://doi.org/10.5507/euj.2020.003

SOI (2020). Special Olympics Global reach report 2020. Accessed via https://media.specialolympics.org/resources/reports/reach-reports/2020-GlobalReach-Report-front.jpg on 9 November 2021.

Shapiro, D. R., \& Pitts, B. G. (2014). What little do we know: Content analysis of disability sport in sport management literature. Journal of Sport Management, 28(6), 657-671. https://doi.org/10.1123/JSM.2013-0258

Townsend, R. C., Smith, B., \& Cushion, C. J. (2015). Disability sports coaching: towards a critical understanding. Sports Coaching Review, 4(2), 80-98.

https://doi.org/10.1080/21640629.2016.1157324.

Townsend, R. C., Huntley, T. D., Cushion, C. J., \& Culver, D. (2021). Infusing disability into coach education and development: a critical review and agenda for change. Physical Education and Sport Pedagogy. Advance online publication. https://doi.org/10.1080/17408989.2021.1873932

Tuakli-Wosornu, Y. A., \& Derman, W. (2018). Contemporary medical, scientific \& social perspectives on para sport. Physical Medicine and Rehabilitation Clinics, 29(2), xviixviii. https://doi.org/10.1016/j.pmr.2018.02.001.

Van Biesen, D., Burns, J., Mactavish, J., Van de Vliet, P., \& Vanlandewijck, Y. (2021). Conceptual model of sport-specific classification for para-athletes with intellectual impairment. Journal of Sports Sciences, 1-11. https://doi.org/10.1080/02640414.2021.1881280.

(C) 2021 by the authors. Submitted for possible open access publication under the terms and conditions of the Creative Commons Attribution (CC BY) license (http://creativecommons.org/licenses/by/4.o/). 